\title{
A Stage-Structured Fishery Model for African Catfish and Nile Tilapia Feeding on Two Food Resources with Harvesting
}

\author{
L. Nankinga $\mathbb{D}^{1,2}$ L. S. Luboobi $\mathbb{D}^{2},{ }^{2}$ J. Y. T. Mugisha, ${ }^{2}$ B. Nannyonga $\mathbb{D}^{2},{ }^{2}$ and L. Carlsson $\mathbb{D}^{3}$ \\ ${ }^{1}$ Department of Mathematics, Kyambogo University, Kyambogo, Uganda \\ ${ }^{2}$ Department of Mathematics, Makerere University, Kampala, Uganda \\ ${ }^{3}$ Division of Mathematics and Physics, Mälardalen University, Västerås, Sweden
}

Correspondence should be addressed to L. Nankinga; lnankinga@kyu.ac.ug

Received 26 August 2021; Accepted 8 December 2021; Published 17 January 2022

Academic Editor: Fernando Simoes

Copyright @ 2022 L. Nankinga et al. This is an open access article distributed under the Creative Commons Attribution License, which permits unrestricted use, distribution, and reproduction in any medium, provided the original work is properly cited.

In this paper, a fishery model for African catfish and Nile tilapia is formulated. This model is used to compare financial profit and biomass outtakes in a two-species system versus single species systems. We consider a stage-structured fish population model consisting of the aforementioned fish species together with two food resources. The model dynamics include cannibalism, predator-prey, feeding, reproduction, maturation, development, mortality, and harvesting. We prove consistency of the model in the sense that the solutions will stay bounded and nonnegative over time. Conditions for local stability of fish-free equilibrium point are established. The simulation results reveal asymptotically stable solutions with coexistence of African catfish, Nile tilapia, and two food resources. The major conclusion from our findings is that fisheries should culture both species to maximize the biomass outtake and financial profit.

\section{Introduction}

Fish is a source of animal protein, providing many key nutrients and calories that are needed for physical and mental development $[1,2]$. Fish contribute 17 percent of animal protein and 7 percent of all proteins and are crucial for over 3 billion people in developing countries [3].

In East Africa, the major species of fish caught are Nile perch (Lates niloticus), Nile tilapia (Oreochromis niloticus), African catfish (Clarias gariepinus), and silver fish (Rastrineobola argentea) to mention but a few. The fishery industry contributes to the gross domestic product (GDP) and has continued to be an important source of foreign exchange earnings through fish exports to the East African region and international markets [4]. Due to the importance of fish to so many people, the demand is very high and has resulted in overfishing and hence a decrease in fish population stock $[5,6]$. Therefore, there is a need to develop sustainable fisheries management practices in East Africa.

Mathematical modeling plays a significant role in the sustainable management of renewable resources. It describes phenomena leading to better prediction, management, and control techniques. Modeling and analysis of multiple species ecological problems were first done by Volterra [7]. Since then, many unstructured ecological models have been formulated and analyzed to study different phenomena [8-12]. Unstructured models, however, treat all individuals as identical and account for reproduction and death as life history processes that are important for population dynamics.

Over the last four decades, there has been a trend towards increased realism of ecological theory. This trend has been supported by introducing physiologically structured population models that distinguish individuals based on physiological characteristics, e.g., size, age, weight, and length. These models include feeding, development, reproduction, and mortality life history processes [13-19].

Stage-structured population models, which still carry a lot of interesting information, are simpler versions of physiologically structured population models and have increased in popularity $[9,19-24]$. Field and laboratory studies have attributed several interesting features of population dynamics of cannibalistic populations, specifically to the occurrence 
of cannibalism [13, 19, 25-30]. Nevertheless, we have not encountered any mathematical models that consider several species including cannibalism.

In this study, we formulate a stage-structured fishery model that resembles the feeding habits of African catfish and Nile tilapia to compare financial profit and biomass outtakes in a two-species system versus single-species systems. The paper is organized as follows: In Section 2, we present the food and feeding habits of African catfish and Nile tilapia. In Section 3, we formulate a stage-structured fishery model with harvesting. In Section 4, we prove the basic properties of the model system (18). Section (5) gives the mathematical analysis of the model. In Section 6, we present the numerical simulations and results of the model equations. We end with a discussion of the results in Section 7.

\section{Food and Feeding Habits of African Catfish and Nile Tilapia}

African catfish (Clarias gariepinus) is a group of domesticated African catfishes of the family of Clariidae, air breathing catfishes. It is widely distributed in African and middle East fresh waters [31-33]. In Uganda, it is found in most natural water bodies, including swamps, streams, rivers, and lakes [34].

Nile tilapia (Oreochromis niloticus) is a species of tilapia, a Cichlid fish native to Africa and Israel. As a food resource, the Nile tilapia is the most important fish species in the tropical and subtropical freshwater, often forming the basis of commercially fisheries in many African countries [35]. In Uganda, Nile tilapia is the second most important farmed aquaculture after African catfish [36]. It is native of lakes Albert, Edward, and George and introduced in the 1950s into Lakes Kyoga and Victoria [37].

Food and feeding habits of fresh water fish species make up the foundation for the development of a management program of fish capture and culture. According to Otieno et al. [38], fish feed mainly on food items that can fit their mouth and what their stomach can digest. As fish grows, the stomach becomes larger, and its digestive system becomes more developed. African catfish is an opportunistic omnivorous feeder ingesting a wide variety of food items such as algae, macrophytes, zooplankton, insects, fish, detritus, amphibians, and sand grains $[39,40]$.

Tesfahun [41] showed that African catfish preferred to feed on animals while plant items were ingested during pursuing other prey organisms. On top of some common resources, such as zoo plankton, smaller specimens tend to ingest more insects while larger specimens mainly prefer fish prey.

Nile tilapia is omnivorous in its feeding habit with plant origin foods as the most dominant food item [41].

\section{Model Formulation}

In this section, we will develop our model system (18). The model we are considering is devoted to the interactions and dynamics of African catfish, Nile tilapia, and two food resources with harvesting. Two food resources are used to capture the difference in feeding habits. African catfish are classified into four stages: small juvenile $X_{1}$, large juvenile $X_{2}$, small adult $X_{3}$, and large adult $X_{4}$. Nile tilapia are composed of two stages: juvenile $Y_{1}$ and adult $Y_{2}$. The stages divide up the the population in body mass intervals. The two food resources are an animal-based food resource $R_{A}$ (e.g., zooplankton) and a plant-based food resource $R_{P}$ (e.g., phytoplankton). African catfish feed on both food resources. In addition, small adult African catfish feed on juvenile Nile tilapia and small juvenile African catfish; large adult African catfish feed on adult Nile tilapia and large juvenile African catfish. Nile tilapia only feed on the plantbased food resources.

The variables used in the model are summarized in Table 1.

Basing on the food and feeding pattern of African catfish and Nile tilapia in Section 2, the assumed feeding habit pattern is summarized in Table 2.

The biomass of small juvenile African catfish $X_{1}$ increases due to somatic growth at a rate $\omega_{1}$, reproduction at a rate $\omega_{4}$ from large adult African catfish, and reproduction at a rate $q v_{3}$ from small adult African catfish, where $q$ is the reproduction fraction and $v_{3}$ is the maturation rate from small adult African catfish to large adult African catfish. Its biomass decreases due to maturation into the large juvenile stage at a rate $v_{1}$, harvesting at a rate $h_{1}$, cannibalism at a rate $c_{1}$, and death due to natural causes at a rate $\mu_{\mathrm{C}}$. The reproduction fraction, $q$, is a parameter determining the fraction of how much of the energy production should be dedicated to reproduction and how much should be dedicated to maturation.

The biomass of large juvenile African catfish $X_{2}$ increases due to the maturation of small juvenile African catfish into the large juvenile stage at a rate $v_{1}$ and the somatic growth at a rate $\omega_{2}$. Its biomass decreases due to maturation of the large juvenile at a rate $v_{2}$, cannibalism at a rate $c_{2}$, harvesting at a rate $h_{2}$, and death due to natural causes at a rate $\mu_{C}$.

The biomass of small adult African catfish biomass $X_{3}$ increases due to maturation of large juvenile African catfish into the small adult stage at a rate $v_{2}$ and somatic growth at a rate $\omega_{3}$. Its biomass decreases due to maturation of small adult African catfish at a rate $(1-q) v_{3}$ to large adult African catfish, reproduction at a rate $q v_{3}$, harvesting at a rate $h_{3}$, and natural death at a rate $\mu_{C}$.

The biomass of large adult African catfish $X_{4}$ increases due to the maturation of small adult African catfish into the large adult stage at a rate $(1-q) v_{3}$. Its biomass decreases due to harvesting at a rate $h_{4}$ and natural death at a rate $\mu_{C}$. Biomass increase due to somatic growth $\omega_{4}$ is lost in reproduction.

The biomass of juvenile Nile tilapia $Y_{1}$ increases due to reproduction of adult Nile tilapia at a rate $\lambda_{2}$ and somatic growth at a rate $\lambda_{1}$. Its biomass decreases due to maturation into the adult stage at a rate $\gamma$, predation at a rate $p_{1}$, harvesting at a rate $f_{1}$, and death due to natural causes at a rate $\mu_{T}$.

The biomass of adult Nile tilapia $Y_{2}$ increases due to maturation into the adult stage at a rate $\gamma$, and it decreases 
TABLE 1: Variables used in the stage-structured model for African catfish, Nile tilapia, and the two food resources.

\begin{tabular}{lc}
\hline Variables & Description \\
\hline$X_{1}$ & Biomass of small juvenile African catfish at time $t$ \\
$X_{2}$ & Biomass of large juvenile African catfish at time $t$ \\
$X_{3}$ & Biomass of small adult African catfish at time $t$ \\
$X_{4}$ & Biomass of large adult African catfish at time $t$ \\
$Y_{1}$ & Biomass of juvenile Nile tilapia at time $t$ \\
$Y_{2}$ & Biomass of adult Nile tilapia at time $t$ \\
$R_{A}$ & Biomass of zooplankton (animal items) at time $t$ \\
$R_{P}$ & Biomass of phytoplankton (plant items) at time $t$ \\
\hline
\end{tabular}

TABle 2: Food preferences of African catfish and Nile tilapia: the elements in the first column eat the elements in the first row in a preferred order, where it prefers the food with the lowest number. If no number exists, then it does not eat the corresponding food. The variable descriptions are given in Table 1.

\begin{tabular}{lcccccc}
\hline Consumer & \multicolumn{5}{c}{ Prey } & \\
& $X_{1}$ & $X_{2}$ & $Y_{1}$ & $Y_{2}$ & $R_{A}$ & $R_{P}$ \\
\hline$X_{1}$ & & & & & 1 & 2 \\
$X_{2}$ & & & & 1 & 2 \\
$X_{3}$ & 2 & & 1 & & 3 & 4 \\
$X_{4}$ & & 2 & & 1 & 3 & 4 \\
$Y_{1}$ & & & & & & 1 \\
$Y_{2}$ & & & & & 1 \\
\hline
\end{tabular}

due to predation at a rate $p_{2}$ harvesting at a rate $f_{2}$ and natural death at a rate $\mu_{\mathrm{T}}$. Biomass increase due to somatic growth $\lambda_{2}$ is lost in reproduction.

According to De Roos et al. [21], in the absence of African catfish and Nile tilapia, the food resource $R_{P}$ is assumed to have semichemostat growth rate $G_{P}\left(R_{P}\right)$,

$$
G_{P}\left(R_{P}\right)=r_{P}\left(R_{P_{\max }}-R_{P}\right),
$$

where $r_{P}$ is the intrinsic growth rate and $R_{P_{\max }}$ is the carrying capacity of food resource, $R_{P}$.

While the food resource $R_{A}$ follows the logistic growth rate $G_{A}\left(R_{A}\right)$,

$$
G_{A}\left(R_{A}\right)=r_{A} R_{A}\left(1-\frac{R_{A}}{R_{A_{\max }}}\right)
$$

where $r_{A}$ is the intrinsic growth rate and $R_{A_{\max }}$ is the carrying capacity of food resource $R_{A}$.

Due to external influx and spatial conditions such as coverage, not all food resources are available to the fish population, see, e.g., [18] for more details and discussions. That is, the fish cannot reach all food $R_{A}$; thus, we introduce a threshold constant, $\Lambda$; the available animalistic food is defined by

$$
\widehat{R}_{A}=\left(R_{A}-\Lambda\right)^{+}:=\max \left(0, R_{A}-\Lambda\right) .
$$

This threshold forces the food resource $R_{A}$ away from zero, thus eliminating the zero growth rate at the origin. A zero growth rate at the origin creates instability in the solution, as well as the possibility of extinction of that food resource. Since the plant food resource, $R_{P}$, follows a semichemostat growth, it has a nonhorizontal tangent line at the origin; therefore, no analytical nor numerical instability occurs, and hence, we are using a zero threshold constant on the plant food resource. We note here that if we instead had used logistic growth rate models without threshold for the food resources, then cyclic solutions would most probably appear, for a deeper discussion of this and related concepts, see, e.g., [42].

3.1. Biological Assumptions. In our model, we make the following assumptions:

(i) African catfish are assumed to have birth size (in fact, the birth size in our model corresponds to the size at which the fish transform from larval into fry, since this is the stage when the fish starts utilizing the food resource) $s_{b}$. The size of small juveniles is in the interval $s_{b} \leq s<s_{1}$, the size of large juveniles is in the interval $s_{1} \leq s<s_{2}$, the size of the small adults is in the interval $s_{2} \leq s<s_{m}$, and the size of large adult African catfish is $s_{m}$

(ii) Nile tilapia are assumed to have birth size $k_{b}$. The size of the juveniles is in the interval $k_{b} \leq s<k_{m}$, and the size of adults is $k_{m}$

(iii) Large adult African catfish of size $s_{m}$ and adult Nile tilapia of size $k_{m}$ do not grow but invest all energy in reproduction

(iv) Small adult African catfish uses the available energy for growth, maturation, and reproduction

(v) Small juvenile African catfish, large juvenile African catfish, and juvenile Nile tilapia use all available energy for growth and maturation

(vi) The growth rate and reproduction rate depend on food availability

(vii) Maturation rates depend on the net biomass production rates

(viii) Consumption of food follows the Holling type II functional response. The net biomass production rates are assumed to equal the balance between ingestion and mass-specific maintenance rates

(ix) At low food densities, the energy intake of juveniles and adults is insufficient to cover their maintenance requirements. As a result, they do not produce biomass. They only produce biomass when their food 
intake is sufficient to cover their maintenance demands

(x) The net biomass production rates for juveniles and adults are assumed to equal the balance between ingestion and maintenance rates for African catfish and Nile tilapia, respectively

3.2. Vital Rates. We adopt De Roos et al.'s [21] derivation of net biomass production rates of individuals in different stages and the maturation rate from one stage to another.

The net biomass production rates of juvenile and adult African catfish are given by

$$
\begin{aligned}
& \omega_{1}=\omega_{2}=\left\{\sigma_{\mathrm{C}} I_{\mathrm{J}}(A+(1-A) P)-T\right\}^{+}, \\
& \omega_{3}=\left\{\sigma_{\mathrm{C}} I_{\mathrm{A}}\left(F_{1}+\left(1-F_{1}\right)(A+(1-A) P)-T\right\}^{+},\right. \\
& \omega_{4}=\left\{\sigma_{\mathrm{C}} I_{\mathrm{A}}\left(F_{2}+\left(1-F_{2}\right)(A+(1-A) P)-T\right\}^{+},\right.
\end{aligned}
$$

where

$$
\begin{aligned}
F_{i} & =\frac{Y_{i}}{H_{C}+Y_{i}}+\left(1-\frac{Y_{i}}{H_{C}+Y_{i}}\right) \frac{X_{i}}{H_{C}+X_{i}}, \mathrm{i}=1,2, \\
A & =\frac{\widehat{R}_{A}}{H_{C}+\widehat{R}_{A}}, \\
P & =\frac{R_{P}}{H_{C}+R_{P}} .
\end{aligned}
$$

Here, $\sigma_{\mathrm{C}}$ is the conversion efficiency of food ingested, $I_{J}$ and $I_{A}$ are the maximum ingestion rates per unit biomass of juvenile and adult African catfish, respectively. $T$ is the mass specific maintenance rate of African catfish, and $H_{C}$ is the half saturation food level of African catfish.

The feeding rate $F_{i}$ is defined in such a way that, for large values of biomass, say $Y_{1}$, we have $F_{1} \approx Y_{1} /\left(H_{C}+Y_{1}\right)$ and for $Y_{1}<<H_{C}$ it follows that $F_{1} \approx X_{1} /\left(H_{C}+X_{1}\right)$. Note also that $0 \leq F_{1} \leq 1$.

The net biomass production rates of juvenile and adult Nile tilapia are given by

$$
\begin{aligned}
& \lambda_{1}=\left\{\sigma_{T} \psi_{J} \frac{R_{P}}{H_{T}+R_{P}}-E\right\}^{+}, \\
& \lambda_{2}=\left\{\sigma_{T} \psi_{A} \frac{R_{P}}{H_{T}+R_{P}}-E\right\}^{+} .
\end{aligned}
$$

where $\sigma_{T}$ is the conversion efficiency of food ingested by Nile tilapia and $\psi_{J}$ and $\psi_{A}$ are the maximum ingestion rates per unit biomass of juvenile and adult Nile tilapia, respectively. $H_{T}$ is the half saturation constant of Nile tilapia, and $E$ is the mass-specific maintenance rate of Nile tilapia.

Natural mortality rates of African catfish and Nile tilapia are given by $\mu_{C}$ and $\mu_{T}$, respectively.

Cannibalistic mortality rates (the cannibalistic and predation mortality rates are in fact proportional to the biomass of the consumed population stage; in some literature, the biomass of the consumed population is included in these expressions) of small adult African catfish on small juvenile African catfish, $c_{1}$, and large adult African catfish on large juvenile African catfish, $c_{2}$, are given by

$$
c_{i}=I_{A} \frac{X_{i+2}}{H_{C}+X_{i}}, i=1,2 \text {. }
$$

Predation rates of small adult African catfish on juvenile Nile tilapia, $p_{1}$, and adult African catfish on adult Nile tilapia, $p_{2}$, are given by

$$
p_{i}=I_{A} \frac{X_{i+2}}{H_{C}+Y_{i}}, i=1,2 .
$$

We use the maturation function

$$
v(\omega, \mu, h, c, z)=\frac{\omega-(\mu+h+c)}{1-(z)^{(1-((\mu+h+c) / \omega))}},
$$

to define the following maturation rates for African catfish

$$
\text { small juvenile } \longrightarrow \text { large juvenile }
$$

$$
v_{1}=v\left(\omega_{1}, \mu_{\mathrm{C}}, h_{1}, c_{1}, \frac{s_{b}}{s_{1}}\right),
$$

large juvenile $\longrightarrow$ small adult

$$
\begin{aligned}
& v_{2}=v\left(\omega_{2}, \mu_{\mathrm{C}}, h_{2}, c_{2}, \frac{s_{1}}{s_{2}}\right), \\
& \text { small adult } \longrightarrow \text { large adult } \\
& v_{3}=v\left(\omega_{3}, \mu_{\mathrm{C}}, h_{3}, 0, \frac{s_{2}}{s_{m}}\right),
\end{aligned}
$$

and for Nile tilapia

$$
\begin{gathered}
\text { juvenile } \longrightarrow \text { adult } \\
\gamma=v\left(\lambda_{1}, \mu_{\mathrm{T}}, f_{1}, p_{1}, \frac{k_{b}}{k_{m}}\right),
\end{gathered}
$$

3.3. The Schematic Diagram of the Model. Based on the model description and assumptions made in Section 3, the dynamics of the system is represented in Figure 1.

3.4. Model Equations. From the assumptions and interrelation between the variables in Table 1 and the parameters in Tables 3-5, as shown in Figure 1, the rates at which the biomass of small juvenile African catfish, large juvenile African catfish, small adult African catfish, large adult African catfish, juvenile Nile tilapia, adult Nile tilapia, and food resources changes are given by the following ordinary differential equations, using the expressions given in Equations (4)-(13)

$$
\begin{gathered}
\frac{d X_{1}}{d t}=\omega_{4} X_{4}+q v_{3} X_{3}+\omega_{1} X_{1}, \\
-\left(v_{1}+\mu_{C}+h_{1}+c_{1}\right) X_{1},
\end{gathered}
$$




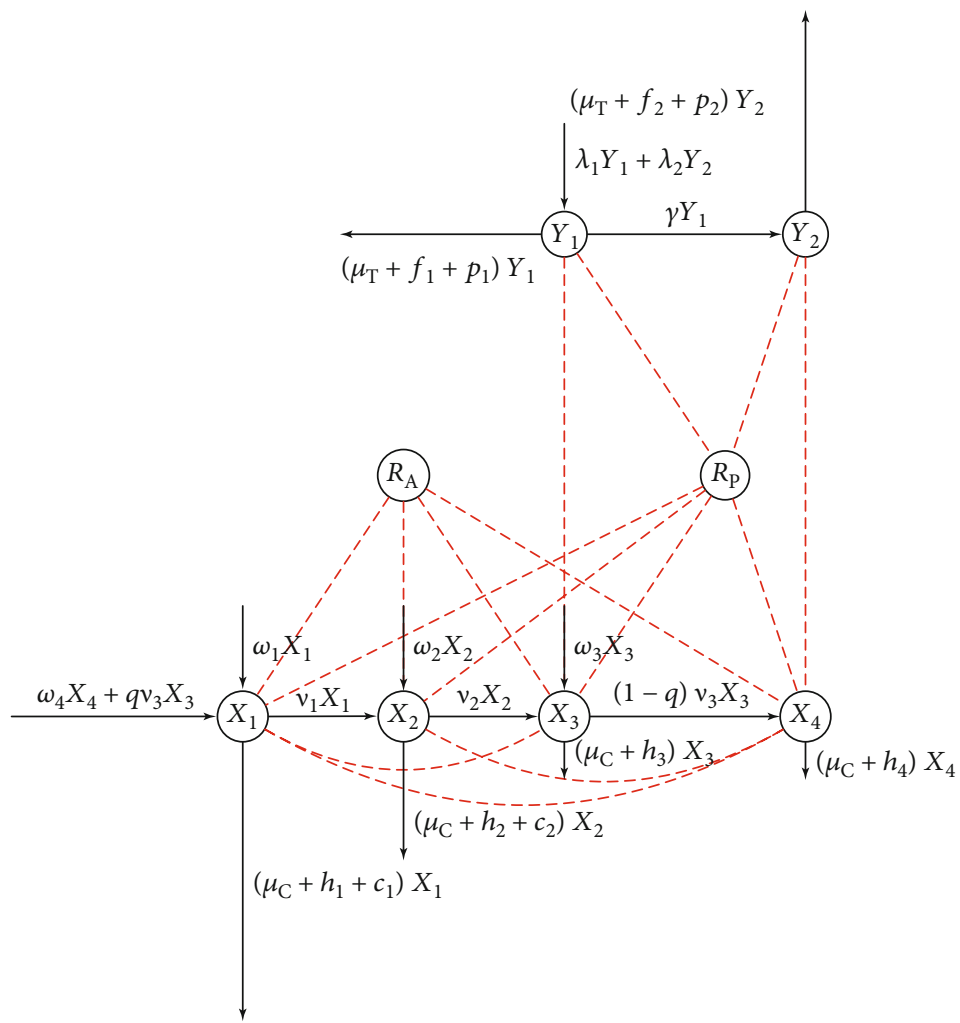

FIgURE 1: Schematic diagram of the dynamics of African catfish, $X_{i}$, Nile tilapia, $Y_{i}$, and two food resources, $R_{A}$ and $R_{P}$; solid arrows indicate growth, reproduction, mortality, and maturation from one stage to another whereas dashed connections show the flow of energy in the foodweb. The remaining parameters in the graph are defined through Equations (4)-(13) (Tables 1 and 3-5).

TABle 3: Parameters for the food resources $R_{A}$ and $R_{P}$.

\begin{tabular}{|c|c|c|c|c|}
\hline Subject and symbol & Definition & Value & Unit & Source \\
\hline$r_{A}$ & Intrinsic growth rate & 0.15 & day $^{-1}$ & {$[57]$} \\
\hline$R_{A_{\max }}$ & Carrying capacity & $4 \times 10^{-3}$ & $\mathrm{~g} / \mathrm{L}$ & {$[58]$} \\
\hline$\Lambda$ & Food threshold constant & $0.01 \times R_{A_{\max }}$ & $\mathrm{g} / \mathrm{L}$ & Assumed \\
\hline$r_{P}$ & Intrinsic growth rate & 0.5 & day $^{-1}$ & {$[56,59]$} \\
\hline$R_{P_{\max }}$ & Carrying capacity & $1.6 \times 10^{-2}$ & $\mathrm{~g} / \mathrm{L}$ & Estimated $^{1}$ \\
\hline
\end{tabular}

${ }^{1}$ Personal communication with biologists A. Larsson and J. Eriksson.

$$
\begin{aligned}
& \frac{d X_{2}}{d t}=v_{1} X_{1}+\omega_{2} X_{2}-\left(v_{2}+\mu_{C}+h_{2}+c_{2}\right) X_{2} \\
& \frac{d X_{3}}{d t}=v_{2} X_{2}+\omega_{3} X_{3}-\left(\nu_{3}+\mu_{C}+h_{3}\right) X_{3} \\
& \frac{d X_{4}}{d t}=(1-q) v_{3} X_{3}-\left(\mu_{C}+h_{4}\right) X_{4}, \\
& \frac{d Y_{1}}{d t}=\lambda_{2} Y_{2}+\lambda_{1} Y_{1}-\left(\gamma+\mu_{\mathrm{T}}+f_{1}+p_{1}\right) Y_{1} \\
& \frac{d Y_{2}}{d t}=\gamma Y_{1}-\left(\mu_{\mathrm{T}}+f_{2}+p_{2}\right) Y_{2}, \\
& \frac{d R_{A}}{d t}=r_{A} R_{A}\left(1-\frac{R_{A}}{R_{A_{\max }}}\right)-F_{A} \widehat{R}_{A},
\end{aligned}
$$

$$
\frac{d R_{P}}{d t}=r_{P}\left(R_{P_{\max }}-R_{P}\right)-F_{P} R_{P}
$$

where

$$
\begin{aligned}
\widehat{R}_{A}= & \left(R_{A}-\Lambda\right)^{+}, \\
F_{A}= & \frac{I_{J}}{H_{C}+\widehat{R}_{A}} X_{1}+\frac{I_{J}}{H_{C}+\widehat{R}_{A}} X_{2}+\left(1-F_{1}\right) \frac{I_{A}}{H_{C}+\widehat{R}_{A}} X_{3} \\
& +\left(1-F_{2}\right) \frac{I_{A}}{H_{C}+\widehat{R}_{A}} X_{4},
\end{aligned}
$$


TABle 4: Parameters for Nile tilapia, denoted $Y$ in our model.

\begin{tabular}{|c|c|c|c|c|}
\hline Parameter & Definition & Value & Unit & Source \\
\hline$k_{b}$ & Size at birth & 0.02 & g & {$[60]$} \\
\hline$k_{m}$ & Maturation size of adults & 176 & g & {$[61]$} \\
\hline E & Maintenance rate & $2.75 \times 10^{-6}$ & day $^{-1}$ & {$[48,50]$} \\
\hline$\mu_{T}$ & Natural mortality rate & $2.75 \times 10^{-4}$ & day $^{-1}$ & {$[52]$} \\
\hline$H_{T}$ & Half saturation constant & $1.26 \times 10^{-2}$ & $\mathrm{~g} / \mathrm{L}$ & {$[53,54]$} \\
\hline$\psi_{J}$ & Maximum ingestion rate for juveniles & $2.75 \times 10^{-2}$ & day $^{-1}$ & {$[49,51]$} \\
\hline$\psi_{A}$ & Maximum ingestion rate for adults & $2.33 \times 10^{-2}$ & day $^{-1}$ & {$[23]$} \\
\hline$\sigma_{T}$ & Conversion efficiency rate for juveniles & 0.5 & - & {$[50]$} \\
\hline
\end{tabular}

Table 5: Parameters for African catfish, denoted $X$ in our model description. MA is an abbreviation of model assumption.

\begin{tabular}{|c|c|c|c|c|}
\hline Parameter & Definition & Value & Unit & Source \\
\hline$s_{b}$ & Birth size & 0.02 & g & {$[55]$} \\
\hline$s_{1}$ & Maturation size to large juveniles & 10 & g & MA \\
\hline$s_{m}$ & Maturation size to small adults & 190 & g & {$[46,62]$} \\
\hline$s_{\max }$ & Maturation size to large adults & 6000 & g & MA \\
\hline$q$ & Reproduction fraction & 0.5 & - & MA \\
\hline$\mu_{C}$ & Natural mortality rate & $2.65 \times 10^{-4}$ & day $^{-1}$ & {$[52]$} \\
\hline$T$ & Maintenance rate & $2.65 \times 10^{-6}$ & day $^{-1}$ & {$[48,50]$} \\
\hline$H_{C}$ & Half saturation constant & $1.38 \times 10^{-2}$ & $\mathrm{~g} / \mathrm{L}$ & {$[53,54]$} \\
\hline$I_{J}$ & Maximum ingestion rate for juveniles & $2.65 \times 10^{-2}$ & day $^{-1}$ & {$[49,51]$} \\
\hline$I_{A}$ & Maximum ingestion rate for adults & $2.25 \times 10^{-2}$ & day $^{-1}$ & {$[23]$} \\
\hline$\sigma_{C}$ & Conversion efficiency rate & 0.5 & - & {$[50]$} \\
\hline
\end{tabular}

$$
\begin{aligned}
F_{P}= & \left(1-\frac{\widehat{R}_{A}}{H_{C}+\widehat{R}_{A}}\right) \frac{I_{J}}{H_{C}+R_{P}} X_{1} \\
& +\left(1-\frac{\widehat{R}_{A}}{H_{C}+\widehat{R}_{A}}\right) \frac{I_{J}}{H_{C}+R_{P}} X_{2} \\
& +\left(1-F_{1}\right)\left(1-\frac{\widehat{R}_{A}}{H_{C}+\widehat{R}_{A}}\right) \frac{I_{A}}{H_{C}+R_{P}} X_{3} \\
& +\left(1-F_{2}\right)\left(1-\frac{\widehat{R}_{A}}{H_{C}+\widehat{R}_{A}}\right) \frac{I_{A}}{H_{C}+R_{P}} X_{4} \\
& +\frac{\psi_{J}}{H_{T}+R_{P}} Y_{1}+\frac{\psi_{A}}{H_{T}+R_{P}} Y_{2},
\end{aligned}
$$

subject to the initial conditions: $X_{1}(0) \geq 0$,

$$
\begin{gathered}
X_{2}(0) \geq 0, X_{3}(0) \geq 0, X_{4}(0) \geq 0 \\
Y_{1}(0) \geq 0, Y_{2}(0) \geq 0, R_{A}(0) \geq 0 \text { and } R_{\mathrm{P}}(0) \geq 0 .
\end{gathered}
$$

\section{Basic Properties of the Model}

We need to show that the model is well-posed in a biologically feasible domain. Since the variables $X_{1}(t), X_{2}(t)$,
$X_{3}(t), X_{4}(t), Y_{1}(t), Y_{2}(t), R_{A}(t), R_{P}(t)$ represent living species, nonnegativity ensures that they never become negative. Boundedness explains that there is a natural restriction to the growth of the population as a consequence of limited resources.

4.1. Positivity. We state a theorem which proves that all solutions of the model system (18) are nonnegative for $t \geq 0$. This proof could be made by considering cases, in the spirit of [43], but since our model would require 15 such cases, we instead prove the nonnegativity using decoupled ODEs.

$$
\text { Let }
$$

$$
\begin{gathered}
\mathbf{u}(t)=\left(u_{1}(t), \cdots, u_{8}(t)\right), \\
:=\left(X_{1}(t), \cdots, X_{4}(t), Y_{1}(t), Y_{2}(t), R_{A}(t), R_{P}(t)\right),
\end{gathered}
$$

we say $\mathbf{u}(t) \geq 0$ if all elements in $\mathbf{u}(t)$ are nonnegative.

To prove the above statement, we need some preliminary theory. Let $\mathbb{R}_{+}=[0, \infty)$. 
Proposition 1. Let $f: \mathbb{R} \times \mathbb{R}_{+} \longrightarrow \mathbb{R}_{+}$and $g: \mathbb{R} \longrightarrow \mathbb{R}$ be integrable. All solutions $v: \mathbb{R}_{+} \longrightarrow \mathbb{R}$ to the ordinary differential equations

$$
\left\{\begin{array}{l}
v^{\prime}(t)=f(v, t)-g(t) v(t), \quad t>0 \\
v(0)=v_{0}
\end{array}\right.
$$

satisfies either case (1) $v(t)>0$ for all $t>0$ if $v_{0}>0$ or case (2) $v(t) \geq 0$ for all $t>0$ if $v_{0}=0$.

Proof. Rewriting the equation we get after multiplication with the integrating factor $h(t)=e^{\int_{0}^{t} g(s) d s}>0$

$$
\frac{d}{d t}(h(t) v(t))=h(t) f(t, v) \geq 0
$$

integrating both sides gives

$$
\int_{0}^{t} \frac{d}{d s}(h(s) v(s) d s=h(t) v(t)-h(0) v(0) \geq 0,
$$

or equivalently

$$
v(t) \geq v(0) e^{-\int_{0}^{t} g(s) d s} .
$$

From this inequality, the two statements above follows instantly.

Theorem 2. The solutions, $\mathbf{u}$, to system (18) satisfy $\mathbf{u}(t) \geq 0$ for all $t \geq 0$ if the initial data is nonnegative, i.e., $\mathbf{u}(0) \geq 0$. If for some $j \in\{1, \cdots, 6\}$, the initial data $u_{j}(0)>0$ then $u_{j}(t)>0$ for all $t>0$.

The ecological interpretation of this theorem is that, on the one hand, if one species is present in the model at the start of simulations, then its biomass is always positive. On the other hand, if we have high harvest pressure or high cannibalism, the species biomass might decline exponentially towards extinction.

Proof (of Theorem 2). That all solutions are nonnegative to system (18) follows as a direct consequence of case (2) in Proposition 1 since all coupled ODEs in system (18), studied as single de-coupled ODEs can be written in the form given in Proposition 1 including the fulfillment of the hypotheses. In the same way, applying case (1) in Proposition 1 proves the second part of the statement.

\subsection{Boundedness}

Theorem 3. All solutions $\mathbf{u}(t)$ of the model system (18) with initial conditions $\mathbf{u}(0) \geq 0$ are uniformly bounded within the region $\Omega=\{\mathbf{u}(t) \geq 0\} \subset \mathbb{R}_{+}^{8}$.
Proof. Let $N(t)$ be the total biomass of system (18) at time $t$ such that

$$
\begin{aligned}
N(t)= & X_{1}(t)+X_{2}(t)+X_{3}(t)+X_{4}(t)+Y_{1}(t) \\
& +Y_{2}(t)+R_{A}(t)+R_{P}(t) .
\end{aligned}
$$

Taking the derivatives of $N(t)$ gives

$$
\begin{aligned}
N^{\prime}(t)= & X_{1^{\prime}}(t)+X_{2^{\prime}}(t)+X_{3^{\prime}}(t)+X_{4^{\prime}}(t)+Y_{1^{\prime}}(t) \\
& +Y_{2^{\prime}}(t)+R_{A}^{\prime}(t)+R_{P}^{\prime}(t),
\end{aligned}
$$

which along the solution path of the model system (18) yields

$$
\begin{aligned}
N^{\prime}(t)= & r_{A} R_{A}\left(1-\frac{R_{A}}{R_{A_{\max }}}\right)-F_{A} \widehat{R}_{A}+r_{P}\left(R_{P_{\max }}-R_{P}\right) \\
& -F_{P} R_{P}+\left(\omega_{1}-\mu_{C}-h_{1}-c_{1}\right) X_{1} \\
& +\left(\omega_{2}-\mu_{C}-h_{2}-c_{2}\right) X_{2}+\left(\omega_{3}-\mu_{C}-h_{3}\right) X_{3} \\
& +\left(\omega_{4}-\mu_{C}-h_{4}\right) X_{4}+\left(\lambda_{1}-\mu_{T}-f_{1}-p_{1}\right) Y_{1} \\
& +\left(\lambda_{2}-\mu_{T}-f_{2}-p_{2}\right) Y_{2} .
\end{aligned}
$$

Substituting Equations (24) and (25) into Equation (34), we get (for convenience, we now use $X_{5}=Y_{1}$ and $X_{6}=Y_{2}$ )

$$
N^{\prime}(t)=r_{A} R_{A}\left(1-\frac{r_{A}}{R_{A_{\max }}}\right)+r_{P}\left(R_{A_{\max }}-R_{P}\right)-\sum_{i=1}^{6} \pi_{i} X_{i},
$$

where

$$
\begin{aligned}
& \pi_{1}=\left(1-\sigma_{C}\right) I_{J}(A+(1-A) P)+T+h_{1}+\mu_{C}+c_{1}, \\
& \pi_{2}=\left(1-\sigma_{C}\right) I_{J}(A+(1-A) P)+T+h_{2}+\mu_{C}+c_{2}, \\
& \pi_{3}=\left(1-\sigma_{C}\right) I_{A}\left(F_{1}+\left(1-F_{1}\right)(A+(1-A) P)\right)+T+h_{3}+\mu_{C}, \\
& \pi_{4}=\left(1-\sigma_{C}\right) I_{A}\left(F_{2}+\left(1-F_{2}\right)(A+(1-A) P)\right)+T+h_{4}+\mu_{C}, \\
& \pi_{5}=\left(1-\sigma_{T}\right) \psi_{J} P .
\end{aligned}
$$

For any $\beta>0$, we add $\beta N(t)$ to both sides of Equation (35) to get

$$
\begin{aligned}
\frac{d N(t)}{d t}+\beta N(t)= & R_{A}\left(r_{A}\left(1-\frac{R_{A}}{R_{A_{\max }}}\right)+\beta\right)+r_{P} R_{P_{\max }} \\
& -\left(r_{P}-\beta\right) R_{P}-\sum_{i=1}^{6}\left(\pi_{i}-\beta\right) X_{i} .
\end{aligned}
$$

Since $\pi_{i}(i=1,2,3,4,5,6)$ are nonnegative continuous functions, each function bounded by a positive constant and $r_{P}>0$, for example, $\pi_{i} \geq T_{1}+\mu_{\mathrm{C}}+c_{1}>0$. Thus, we 
define $\beta=\min \left\{\pi_{1}, \pi_{2}, \pi_{3}, \pi_{4}, \pi_{5}, \pi_{6}, r_{P}\right\}$. This now implies that

$$
\begin{array}{r}
\frac{d N(t)}{d t}+\beta N(t) \leq r_{P} R_{P_{\text {max }}}, \\
+R_{A}\left(r_{A}\left(1-\frac{R_{A}}{R_{A_{\max }}}\right)+\beta\right) .
\end{array}
$$

We study the right hand side

$$
f\left(R_{A}\right)=r_{P} R_{P_{\max }}+R_{A}\left(r_{A}\left(1-\frac{R_{A}}{R_{A_{\text {max }}}}\right)+\beta\right),
$$

which is a second degree polynomial in $R_{A}$, and hence, attains its maximum value at

$$
R_{A}=\frac{R_{A_{\max }}\left(r_{A}+\beta\right)}{2 r_{A}} .
$$
yields

Substituting $R_{A}$ from Equation (41) into inequality (38)

$$
\frac{d N(t)}{d t}+\beta N(t) \leq r_{P} R_{P_{\max }}+\frac{R_{A_{\max }}\left(r_{A}+\beta\right)^{2}}{4 r_{A}} .
$$

Using the product rule of derivatives on the left hand side and integrating from 0 to $t$ on both sides give the bound

$$
N(t) \leq \frac{\Phi}{\beta}\left(1-e^{-\beta t}\right)+N(0) e^{-\beta t},
$$

where $N(0)$ is the total biomass at time $t=0$ and

$$
\Phi=r_{P} R_{P_{\max }}+\frac{R_{A_{\max }}\left(r_{A}+\beta\right)^{2}}{4 r_{A}}>0 .
$$

By Theorem 2, we get the bound

$$
0 \leq N(t) \leq \max \left\{N(0), \frac{\Phi}{\beta}\right\},
$$

for all $t \geq 0$.

Hence, the solutions of the model in $\mathbb{R}_{+}^{8}$ are confined in the region

$$
\Omega=\left(X_{1}, X_{2}, X_{3}, X_{4}, Y_{1}, Y_{2}, R_{A}, R_{P}\right) \in \mathbb{R}_{+}^{8},
$$

$: 0 \leq N(t) \leq \max \{N(0), \Phi / \beta\}$. Therefore, we conclude that the model is biologically and mathematically wellposed in the region $\Omega$.

\section{Analysis of the Model}

5.1. Existence of Equilibrium Points. The points at which the derivatives of the system (18) are zero will be referred to as equilibrium points or steady state solutions. The system has six possible feasible equilibrium points. The vector below indicates the values of $\left(X_{1}, X_{2}, X_{3}, X_{4}, Y_{1}, Y_{2}, R_{A}, R_{P}\right)$.

$E^{1}$ The fish-free with plant based food resource equilibrium point $\left(0,0,0,0,0,0,0, R_{P_{\max }}\right)$.

$E^{2}$ The fish-free with two food resources equilibrium point $\left(0,0,0,0,0,0, R_{A_{\max }}, R_{P_{\max }}\right)$.

$E^{3}$ The African catfish free equilibrium point $(0,0,0,0$, $\left.Y_{1}^{\mathrm{ao}}, Y_{2}^{\mathrm{ao}}, 0, R_{P}^{\mathrm{ao}}\right)$.

$E^{4}$ The African catfish free equilibrium point $(0,0,0,0$, $\left.Y_{1}^{\text {aoao }}, Y_{2}^{\text {aoa }}, R_{A}^{\text {aoao }}, R_{P}^{\text {aoao }}\right)$.

$E^{5}$ The Nile tilapia free equilibrium point $\left(X_{1}^{\dagger \dagger}, X_{2}^{\dagger \dagger}, X_{3}^{\dagger \dagger}\right.$, $\left.X_{4}^{\dagger \dagger}, 0,0, R_{A}^{\dagger \dagger}, R_{P}^{\dagger \dagger}\right)$.

$E^{6}$ The coexistence equilibrium point $\left(X_{1}^{* *}, X_{2}^{* *}, X_{3}^{* *}\right.$, $\left.X_{4}^{* *}, Y_{1}^{* *}, Y_{2}^{* *}, R_{A}^{* *}, R_{P}^{* *}\right)$.

5.2. Local Stability Analysis. In this subsection, we investigate the local stability of each of the equilibrium solutions of the model system (18) obtained by calculating the Jacobian matrix $J$ corresponding to each of the equilibrium points.

Theorem 4. The equilibrium points with zero animalistic food resource $E^{1}$ and $E^{3}$ are all unstable.

Proof. The Jacobian matrix evaluated at equilibrium point $E^{1}\left(0,0,0,0,0,0,0, R_{P_{\max }}\right)$ is given by

$$
J\left(E^{1}\right)=\left[\begin{array}{cccccccc}
b_{11} & 0 & q v_{3} & \omega_{4} & 0 & 0 & 0 & 0 \\
v_{1} & b_{22} & 0 & 0 & 0 & 0 & 0 & 0 \\
0 & v_{2} & b_{33} & 0 & 0 & 0 & 0 & 0 \\
0 & 0 & b_{43} & b_{44} & 0 & 0 & 0 & 0 \\
0 & 0 & 0 & 0 & b_{55} & \lambda_{2} & 0 & 0 \\
0 & 0 & 0 & 0 & \gamma & b_{66} & 0 & 0 \\
0 & 0 & 0 & 0 & 0 & 0 & r_{A} & 0 \\
0 & 0 & 0 & 0 & 0 & 0 & 0 & -r_{P}
\end{array}\right],
$$

where

$b_{11}=\omega_{1}-\left(v_{1}+\mu_{C}+h_{1}\right), \quad b_{22}=\omega_{2}-\left(v_{2}+\mu_{C}+h_{2}\right), \quad b_{33}$ $=\omega_{3}-\left(v_{3}+\mu_{C}+h_{3}\right), b_{43}=(1-q) v_{3}, b_{44}=-\left(\mu_{C}+h_{4}\right), b_{55}$ $=\lambda_{1}-\left(\gamma+\mu_{T}+f_{1}\right)$, and $b_{66}=-\left(\mu_{T}+f_{2}\right)$. We observe that the seventh and eighth columns contain only diagonal terms which form two eigenvalues $r_{A}$ and $-r_{P}$ out of eight eigenvalues. Since $r_{A}$ is positive, we thus have a nonstable equilibrium point.

Similarly, using the method above, the equilibrium point $E^{3}$ is unstable.

Theorem 5. The fish-free equilibrium point $E^{2}(0,0,0,0,0,0$, $\left.R_{A_{\max }}, R_{P_{\max }}\right)$ is locally asymptotically stable if $R_{C}<1$ and $R_{T}<1$ and unstable otherwise. 
Proof. The local stability of the equilibrium point $E^{2}$ is investigated using the eigenvalues or trace determinant criteria of the Jacobian matrix. An equilibrium point is locally asymptotically stable if the Jacobian matrix evaluated at that point has negative eigenvalues or has a negative trace and a positive determinant.

The Jacobian matrix evaluated at equilibrium point $E^{2}\left(0,0,0,0,0,0, R_{A_{\max }}, R_{P_{\max }}\right)$ is given by

$$
J\left(E^{2}\right)=\left[\begin{array}{cccccccc}
a_{11} & 0 & a_{13} & a_{14} & 0 & 0 & 0 & 0 \\
a_{21} & a_{22} & 0 & 0 & 0 & 0 & 0 & 0 \\
0 & a_{32} & a_{33} & 0 & 0 & 0 & 0 & 0 \\
0 & 0 & a_{34} & a_{44} & 0 & 0 & 0 & 0 \\
0 & 0 & 0 & 0 & a_{55} & a_{56} & 0 & 0 \\
0 & 0 & 0 & 0 & a_{65} & a_{66} & 0 & 0 \\
0 & 0 & 0 & 0 & 0 & 0 & a_{77} & 0 \\
0 & 0 & 0 & 0 & 0 & 0 & 0 & a_{88}
\end{array}\right]
$$

where

$a_{11}=\omega_{1}-\left(v_{1}+\mu_{C}+h_{1}\right), \quad a_{13}=q v_{3}, a_{14}=\omega_{4}, a_{21}=v_{1}$, $a_{22}=\omega_{2}-\left(v_{2}+\mu_{C}+h_{2}\right), a_{32}=v_{2}, a_{33}=\omega_{3}-\left(v_{3}+\mu_{C}+h_{3}\right)$, $a_{43}=(1-q) v_{3}, \quad a_{44}=-\left(\mu_{C}+h_{4}\right), \quad a_{55}=\lambda_{1}-\left(\gamma+\mu_{T}+f_{1}\right)$, $a_{56}=\lambda_{2}, J_{65}=\gamma, a_{66}=-\left(\mu_{T}+f_{2}\right), a_{77}=-r_{A}$, and $a_{88}=-r_{P}$.

Observe that if the harvesting is high enough, then $a_{i i}<0$ for $i=1,2, \cdots, 6$. We need to show that all eigenvalues of $J\left(E^{2}\right)$ are negative. As the seventh and eighth columns contain only diagonal terms which form the two eigenvalues $r_{A}$ and $-r_{P}$, the other six eigenvalues can be obtained from the submatrix $J_{1}\left(E^{2}\right)$ formed by excluding the seventh and eighth rows and columns of $J\left(E^{2}\right)$. Hence, we have

$$
J_{1}\left(E^{2}\right)=\left[\begin{array}{cccccc}
a_{11} & 0 & a_{13} & a_{14} & 0 & 0 \\
a_{21} & a_{22} & 0 & 0 & 0 & 0 \\
0 & a_{32} & a_{33} & 0 & 0 & 0 \\
0 & 0 & a_{43} & a_{44} & 0 & 0 \\
0 & 0 & 0 & 0 & a_{55} & a_{54} \\
0 & 0 & 0 & 0 & a_{65} & a_{66}
\end{array}\right] .
$$

The eigenvalues of the matrix $J_{1}\left(E^{2}\right)$ are the roots of the characteristic equation $\operatorname{det}\left(J_{1}\left(E^{2}\right)-\lambda I\right)=0$. That is

$\operatorname{det}\left[\begin{array}{cccccc}a_{11}-\lambda & 0 & a_{13} & a_{14} & 0 & 0 \\ a_{21} & a_{22}-\lambda & 0 & 0 & 0 & 0 \\ 0 & a_{32} & a_{33}-\lambda & 0 & 0 & 0 \\ 0 & 0 & a_{43} & a_{44}-\lambda & 0 & 0 \\ 0 & 0 & 0 & 0 & a_{55}-\lambda & a_{56} \\ 0 & 0 & 0 & 0 & a_{65} & a_{66}-\lambda\end{array}\right]$
$=0$, which is equal to solving (since this is a block diagonal matrix) $\operatorname{det} A \operatorname{det} B=0$ where

$$
\begin{aligned}
& A=\left[\begin{array}{cccc}
a_{11}-\lambda & 0 & a_{13} & a_{14} \\
a_{21} & a_{22}-\lambda & 0 & 0 \\
0 & a_{32} & a_{33}-\lambda & 0 \\
0 & 0 & a_{43} & a_{44}-\lambda
\end{array}\right], \\
& B=\left[\begin{array}{cc}
a_{55}-\lambda & a_{56} \\
a_{65} & a_{66}-\lambda
\end{array}\right] .
\end{aligned}
$$

From

$$
\operatorname{det}\left[\begin{array}{cc}
a_{55}-\lambda & a_{56} \\
a_{65} & a_{66}-\lambda
\end{array}\right]=0 .
$$

We get a second degree characteristic equation given by

$$
\left(a_{55}-\lambda\right)\left(a_{66}-\lambda\right)-a_{56} a_{65}=0,
$$

that is

$$
\lambda^{2}-\left(a_{55}+a_{66}\right) \lambda+a_{55} a_{66}-a_{56} a_{65}=0 .
$$

Using the Routh-Hurwitz criterion, the solutions have negative real parts if

$$
\begin{array}{r}
-\left(a_{55}+a_{66}\right)>0, \\
a_{55} a_{66}-a_{56} a_{65}>0,
\end{array}
$$

Now

$$
-\left(a_{55}+a_{66}\right)>0
$$

is equivalent to

$$
\gamma+2 \mu_{T}+f_{1}-\lambda_{1}+f_{2}>0 .
$$

That is, this inequality is satisfied if

$$
\begin{aligned}
f_{1}+f_{2} & >\lambda_{1}-\gamma-2 \mu_{T}, \\
a_{55} a_{66}-a_{56} a_{65} & >0,
\end{aligned}
$$

is equivalent to

$$
\left(\gamma+\mu_{T}+f_{1}-\lambda_{1}\right)\left(\mu_{T}+f_{2}\right)-\lambda_{2} \gamma>0 .
$$

That is, if $f_{1}>\lambda_{1}-\gamma-\mu_{T}$, we get

$$
\left(1-\frac{\lambda_{2} \gamma}{\left(\gamma+\mu_{T}+f_{1}-\lambda_{1}\right)\left(\mu_{T}+f_{2}\right)}\right)>0 .
$$


This inequality is satisfied if and only if

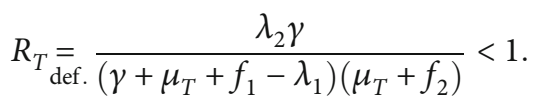

Here, $R_{T}$ is the recovery potential of Nile tilapia based on growth in biomass.

Considering

$$
\operatorname{det}\left[\begin{array}{cccc}
a_{11}-\lambda & 0 & a_{13} & a_{14} \\
a_{21} & a_{22}-\lambda & 0 & 0 \\
0 & a_{32} & a_{33}-\lambda & 0 \\
0 & 0 & a_{43} & a_{44}-\lambda
\end{array}\right]=0 .
$$

We get a fourth degree characteristic equation given by

$$
A_{0} \lambda^{4}+A_{1} \lambda^{3}+A_{2} \lambda^{2}+A_{3} \lambda+A_{4}=0
$$

where

$$
\begin{aligned}
A_{0}= & 1, \\
A_{1}= & -\left(a_{11}+a_{22}+a_{33}+a_{44}\right), \\
A_{2}= & \left(a_{33} a_{22}+a_{33} a_{11}+a_{44} a_{33}+a_{44} a_{22}+a_{44} a_{11}+a_{22} a_{11}\right), \\
A_{3}= & -\left(a_{13} a_{21} a_{32}+a_{44} a_{33} a_{22}+a_{44} a_{33} a_{11}\right. \\
& \left.+a_{33} a_{22} a_{11}+a_{44} a_{22} a_{11}\right), \\
A_{4}= & -a_{14} a_{21} a_{32} a_{43}+a_{44} a_{13} a_{21} a_{32}+a_{44} a_{33} a_{22} a_{11} .
\end{aligned}
$$

Using Routh-Hurwitz criteria [44, 45], the roots of the characteristic Equation (63) are negative or have negative real parts if

$$
\begin{aligned}
A_{1} & >0, \\
A_{1} A_{2}-A_{0} A_{3} & >0, \\
\left(A_{1} A_{2}-A_{0} A_{3}\right) A_{3}-A_{1}^{2} A_{4} & >0, \\
A_{4} & >0 .
\end{aligned}
$$

Criteria 1. That is, $A_{1}>0$ is true, provided $a_{11}+a_{22}+$ $a_{33}+a_{44}<0$, which is true if the harvesting rates are high enough.

Criteria 2. We have to show that $A_{1} A_{2}-A_{0} A_{3}>0$; that is, we need to check if the left hand side is greater than zero; the left hand side is

$$
A_{1} A_{2}-A_{0} A_{3}=-\left(a_{11}+a_{22}+a_{33}+a_{44}\right) \text {, }
$$

$$
\begin{aligned}
\left(a_{11} a_{22}\right. & \left.+a_{11} a_{33}+a_{11} a_{44}+a_{22} a_{33}+a_{22} a_{44}+a_{33} a_{44}\right) \\
& -1\left(-a_{11} a_{22} a_{33}-a_{21} a_{13} a_{32}-a_{11} a_{22} a_{44}\right. \\
& \left.-a_{11} a_{33} a_{44}-a_{22} a_{33} a_{44}\right) \\
= & a_{11}^{2} a_{22}-a_{11}^{2} a_{33}-a_{11}^{2} a_{44}-a_{11} a_{22}^{2}-4 a_{11} a_{22} a_{33} \\
& -2 a_{11} a_{22} a_{44}-a_{11} a_{33}^{2}-2 a_{11} a_{33} a_{44}-a_{11} a_{44}^{2} \\
& -a_{22}^{2} a_{33}-a_{22}^{2} a_{44}-a_{22} a_{33}^{2}-2 a_{22} a_{33} a_{44}-a_{22} a_{44}^{2} \\
& -a_{33}^{2} a_{44}-a_{33} a_{44}^{2}+a_{21} a_{13} a_{32} .
\end{aligned}
$$

All terms in the right hand side of Equation (67) are greater than zero (since $a_{i i}<0, i=1,2,3,4$ ) with the possible exception of $+a_{21} a_{13} a_{32}$. From the definitions, $+a_{21} a_{13} a_{32}$ is equivalent to $q v_{1} v_{2} v_{3}$ which is also greater than zero, hence showing that $A_{1} A_{2}-A_{0} A_{3}>0$.

Criteria 3 . The analytical proof of

$$
\left(A_{1} A_{2}-A_{0} A_{3}\right) A_{3}-A_{1}^{2} A_{4}>0 \text {, }
$$

is very hard. Instead, we observe the graphs in Figure 2 where they show that this criterion is satisfied, since at the harvesting rate zero, the graph of $\left(A_{1} A_{2}-A_{0} A_{3}\right) A_{3}-A_{1}^{2} A_{4}$ against harvesting rate starts at a positive value and is increasing. Figure 2(a) shows the values of this expression for a larger set of harvesting rates. Figure 2(b) shows that this expression is positive even for small values of the harvesting rate.

Finally, Criteria 4: $A_{4}>0$ is the same as

$$
-a_{14} a_{21} a_{32} a_{43}+a_{44} a_{13} a_{21} a_{32}+a_{44} a_{33} a_{22} a_{11}>0 .
$$

This is equivalent to

$$
R_{C}=M N<1,
$$

where

$$
\begin{gathered}
M=\frac{q\left(\mu_{\mathrm{C}}+h_{4}\right)+(1-q) \omega_{4}}{\mu_{C}+h_{4}}, \\
N=\frac{v_{1} v_{2} v_{3}}{\left(v_{1}+\mu_{C}+h_{1}-\omega_{1}\right)\left(\nu_{2}+\mu_{C}+h_{2}-\omega_{2}\right)\left(\nu_{3}+\mu_{C}+h_{3}-\omega_{3}\right)} .
\end{gathered}
$$

The function $R_{C}$ can be viewed as the recovery potential of African catfish based on growth in biomass. The recovery potential represents the net generational biomass production (per unit body mass) in a virgin environment [24]. Thus, by the Routh-Hurwitz criterion, the fish-free equilibrium is asymptotically locally stable iff $R_{C}<1$ and $R_{T}<1$, defined by Equations (61) and (71) which completes the proof.

The Jacobian matrices evaluated at the equilibrium points $E^{4}, E^{5}$, and $E^{6}$ lead to characteristic polynomials of degree eight whose eigenvalues are too complex to be obtained analytically. Therefore, we revert to numerical simulations, see Section 6 . 


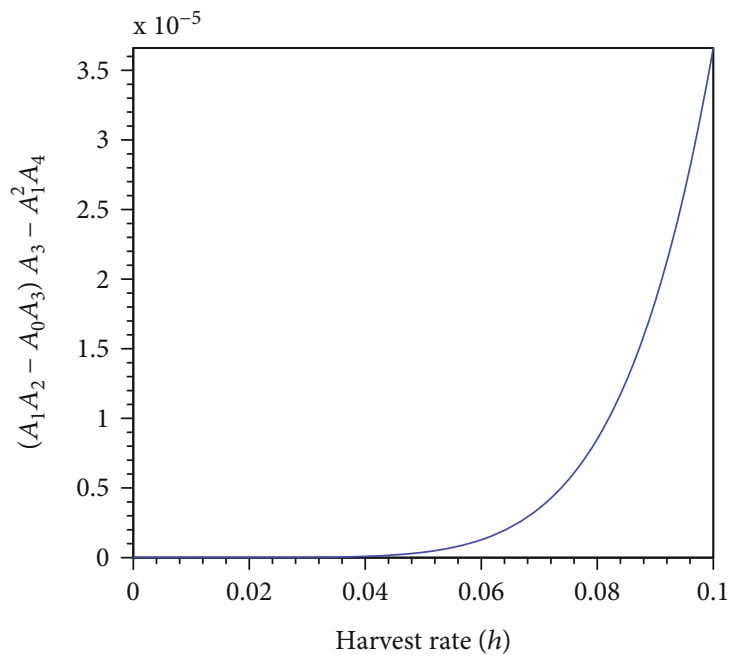

(a)

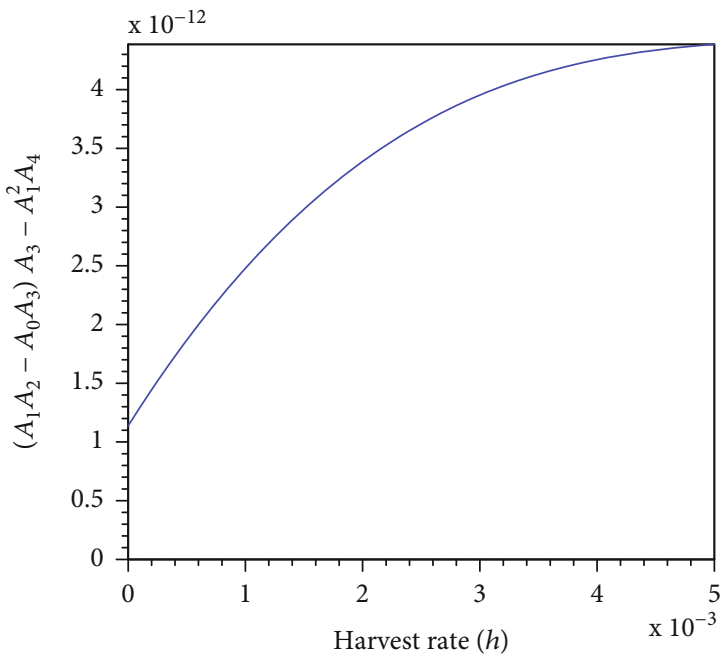

(b)

Figure 2: Graphical representation of Routh-Hurwitz Criteria 3, where the $y$-axis represents the expression $\left(A_{1} A_{2}-A_{0} A_{3}\right) A_{3}-A_{1}^{2} A_{4}$ and the $x$-axis represents the harvesting rate. Other parameter values used can be found in Tables 3-5.

\section{Numerical Simulations}

In this section, we carry out numerical simulations using MATLAB to investigate coexistence and stability of African catfish, Nile tilapia, and the two types of food resources at steady state. We further investigate proportional harvesting in a system that has both African catfish and Nile tilapia, only African catfish, and only Nile tilapia, respectively, in terms of biomass yield and financial profits at steady state.

6.1. Model Parameterization. The parameter values are obtained from the literature review when possible. The maturation size of African catfish is $28-30 \mathrm{~cm}$ in total body length [46], and the maturation size of Nile tilapia is $20.8 \mathrm{~cm}$ [47].

We used the standard quarter-power scaling law [48-50] to estimate: the maximum ingestion rate with proportionality constant for the maximum ingestion rate $0.01[49,51]$, maintenance rate with proportionality constant 0.01 [48, $50]$, and mortality rate with proportionality constant 0.001 [52]. Following Lessmark [53] and Byström and GarcíaBerthou [54], we used uniform half saturation constants for Nile tilapia and African catfish, evaluated by the mean weight of, respectively, species.

In the model, the birth size of African catfish is 0.02 grams [55]. The maturation size of large juveniles and large adults is assumed to be $30 \mathrm{~cm}$ and $100 \mathrm{~cm}$, respectively. Since our model is based on weight, we use the following relation between length, $L(\mathrm{~cm})$, and weight, $W$ (grams)

$$
W=c_{1} L^{c_{2}}
$$

where $c_{1}=0.002$ and $c_{2}=3.232$ for the African catfish [10] and $c_{1}=0.019$ and $c_{2}=3.01$ for the Nile tilapia [56]. Conversion efficiency rate is assumed to be independent of food type and fish species and is set to $0.5[49,50]$. The maximum ingestion rates of adult individuals are assumed to be 0.85 times the ingestion rates of juveniles for both species [23]. Finally, we assume an equal natural mortality rate at all stages.

The parameter values used in the model are summarized in Tables 3-5.

6.2. Numerical Stability Analysis of $E^{4}, E^{5}$, and $E^{6}$. The remaining equilibrium points to investigate the stability are $E^{4}, E^{5}$, and $E^{6}$.

The stability of equilibrium point $E^{4}\left(0,0,0,0, Y_{1}^{\text {aoao }}\right.$, $Y_{2}^{\text {aoa }}, R_{A}^{\text {aoa }}, R_{P}^{\text {aoao }}$ ) occurs when $0.51 \leq h_{i} \leq 0.77, i=1,2,3,4$. We tested the stability by running the model with different harvesting rates $h=\left(0.77,0.77,0.77,0.77, f_{1}, f_{2}\right)$, using one hundred different initial values of the form $\left(X_{1}, X_{2}, X_{3}, X_{4}\right.$, $\left.Y_{1}, Y_{2}, R_{\mathrm{A}}, R_{\mathrm{P}}\right)$, taken randomly from the parameter space. In all these simulations, we ended up with the equilibrium solution $E^{4}$; we therefore conclude that $E^{4}$ is a stable equilibrium point provided that the harvesting rate of the catfish population is high enough and $f_{1}$ and $f_{2}$ are smaller than 0.005 .

In an analogous manner, we established the stability of $E^{5}$ when both $f_{1}$ and $f_{2}$ exceed 0.01 and $h_{i} \leq 0.005$ for $i=1,2,3,4$.

Finally, when all harvesting rates are low, the simulations always converge to the equilibrium point $E^{6}$.

6.3. Simulation Results. Our simulations are stable in the sense that when positive initial values are used, the solutions approach the positive steady state (all simulations shown in other figures in this paper have reached steady state) as indicated by Figure 3 which shows the dynamics of the solutions to system (18). This signifies coexistence and stability of African catfish, Nile tilapia, and the two different food resources at steady state.

Recently, Lundström et al. [23] adopted the model introduced by De Roos et al. [21], in which Lundström et al. compared the properties between a stage-structured 


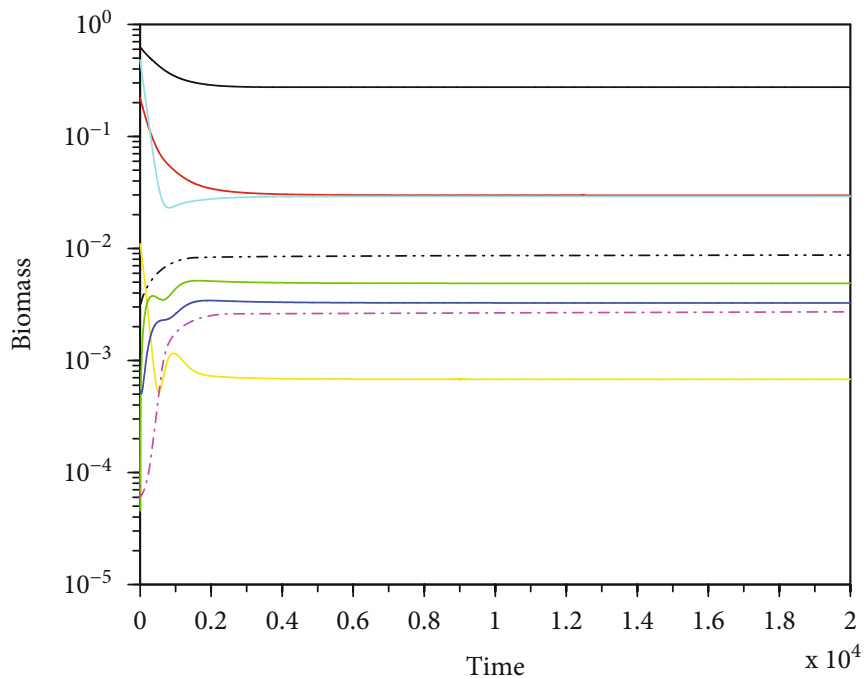

Figure 3: Dynamics of African catfish, Nile tilapia, and two different food resources. The $y$-axis shows the biomass in grams per litre (in a logarithmic scale) for each fish compartment together with the food resources. The initial values are chosen positive; all harvest rates are set to 0.005 per day; other parameter values can be found in Tables 3-5.
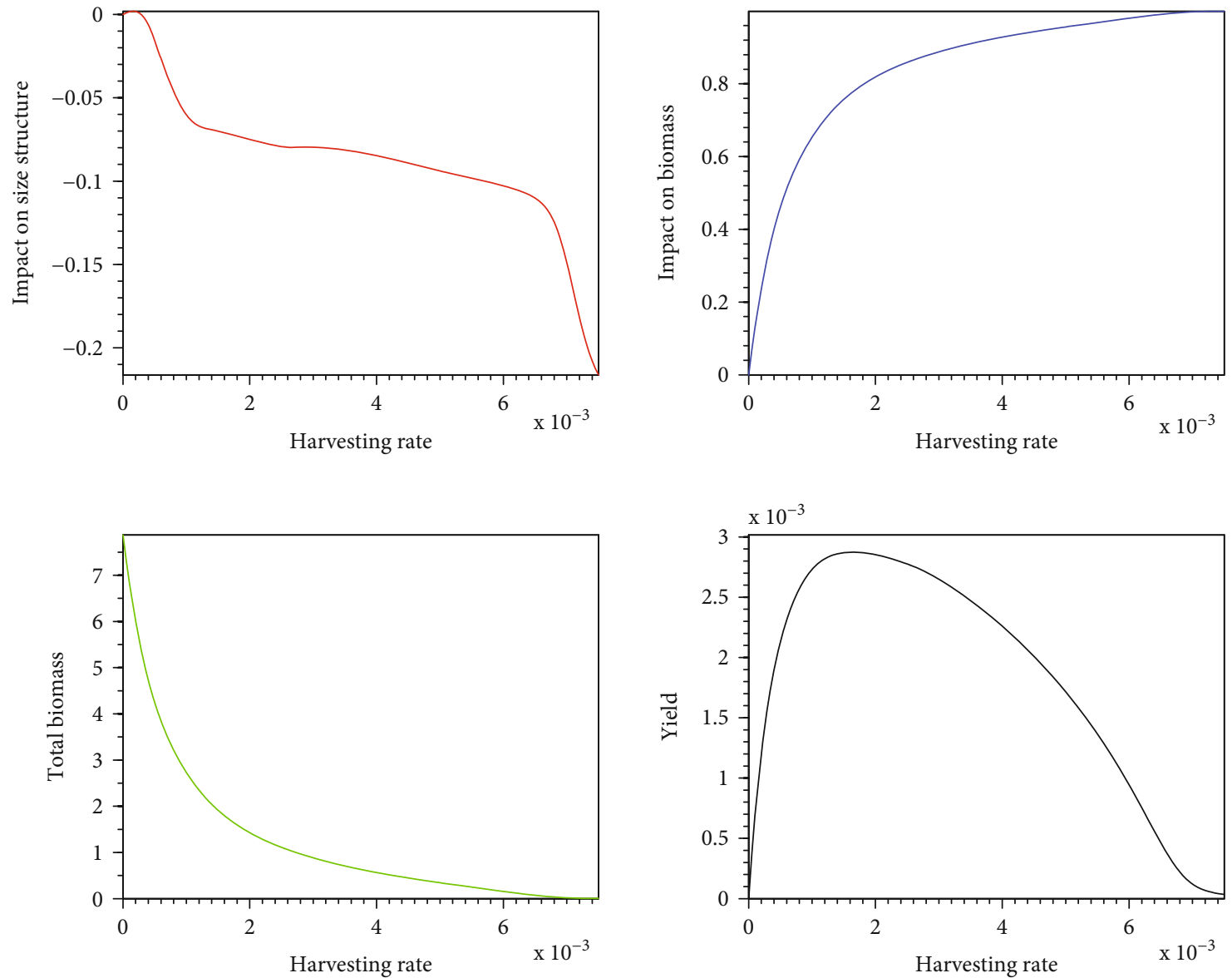

FIGURE 4: Simulation results, using system (18), including both African catfish and Nile tilapia. The figures show the dependence of impact on size structure (red curve), impact on biomass (blue curve), total biomass (green curve), and yield (black curve) with respect to equal harvesting rates, i.e., $\vec{h}=(h, h, h, h, h, h)$. The initial values are chosen positive, and other parameter values can be found in Tables $3-5$. 

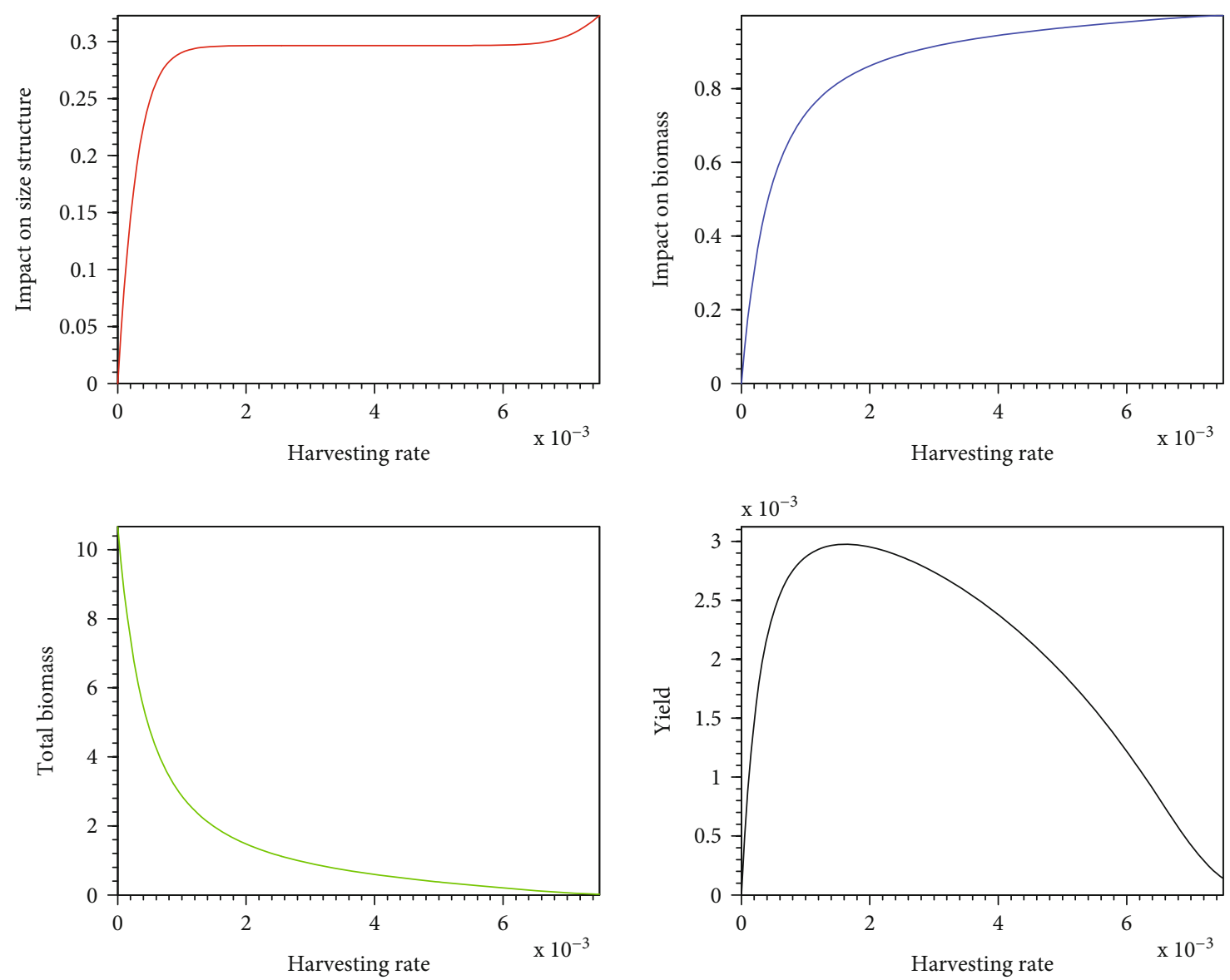

FIGURE 5: Simulation results, using system (18), including only the Nile tilapia. The figures show the dependence of impact on size structure (red curve), impact on biomass (blue curve), total biomass (green curve), and yield (black curve) with respect to equal harvesting rates, i.e., $\vec{h}=(h, h)$. The initial values are chosen positive, and other parameter values can be found in Tables 3-5.

fish population model with an age-structured population model. They investigated how harvesting strategies that qualify for pretty good yield can account for conservation and concluded that equal harvesting rate of juveniles and adults is always a good strategy. We present some of these properties, using equal harvesting in all stages in our model: Figure 4 for African catfish and Nile tilapia and Figure 5 Nile tilapia only.

One result by Lundström et al. [23] is that when studying the impact of harvesting on population size structure, they found a positive change in the fraction of juveniles compared to adults in the population. In contrast to this, we find that the impact of population size structure may have a negative dependence on the harvest rate, see Figure 4. This negative impact occurs because African catfish is cannibalistic and predates on Nile tilapia, in that adults feed on juveniles, and this reduces the fraction of juveniles in the system. When we simulate the single fish species Nile tilapia (see Figure 5), our model shows similar results as in [23]; in particular, the impact on size structure is positively dependent on the harvesting rate, which signifies that increasing the uniform harvesting rate there is an increase in the fraction of juveniles.
In fisheries, one can use different mesh sizes in the nets; we therefore have modeled system (18) under a specific type of harvesting rate. In Figures 6 and 7, we consider unbalanced harvesting rates on juveniles and adults for both African catfish and Nile tilapia, i.e., harvesting pressure $\vec{h}=((1-p) h,(1-p) h, p h, p h,(1-p) h, p h)$, where the proportion $0 \leq p \leq 1$. The figures display the biomass yield (Figure 6) and financial profit (Figure 7) with respect to different harvesting rates, $h$, and proportions, $p$. The maximum sustainable biomass yield and maximum sustainable financial profits are attained when $p$ is large; that is, we mainly harvest adults.

In fisheries, one can harvest the fish stock by catch and release, for example, with a bottle trap or a fyke net; we therefore model system (18) with variable harvesting rates on all fish compartments. Table 6 shows the results after using pattern search to find optimal harvest rates that maximize biomass yield and financial profit for both species in the system, only Nile tilapia in the system, and only African catfish in the system. Our finding is that harvesting in a system that has both Nile tilapia and African catfish gives the highest biomass yield and financial profit (the optimal values for biomass yield and financial profit in Table 6 are found at 


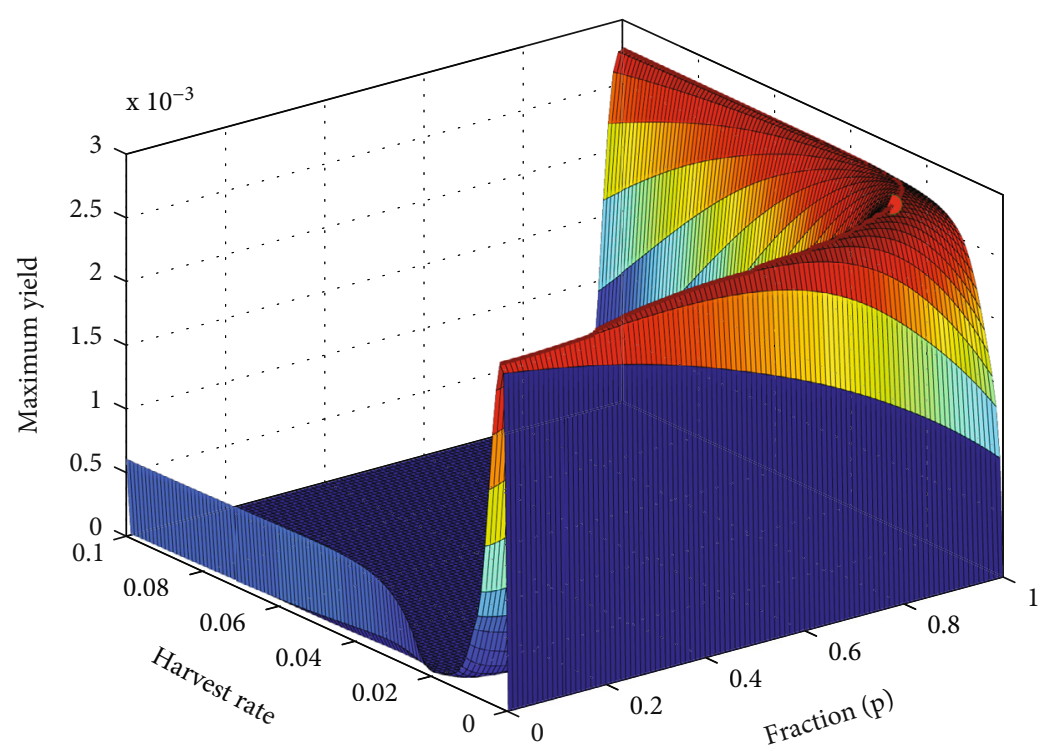

FIGURE 6: Simulation results, using system (18), including both African catfish and Nile tilapia with proportional harvesting rates, i.e., $\vec{h}_{p}=((1-p) h,(1-p) h, p h, p h,(1-p) h, p h)$ where $0 \leq p \leq 1$. The initial values are chosen positive, and other parameter values can be found in Tables $3-5$.

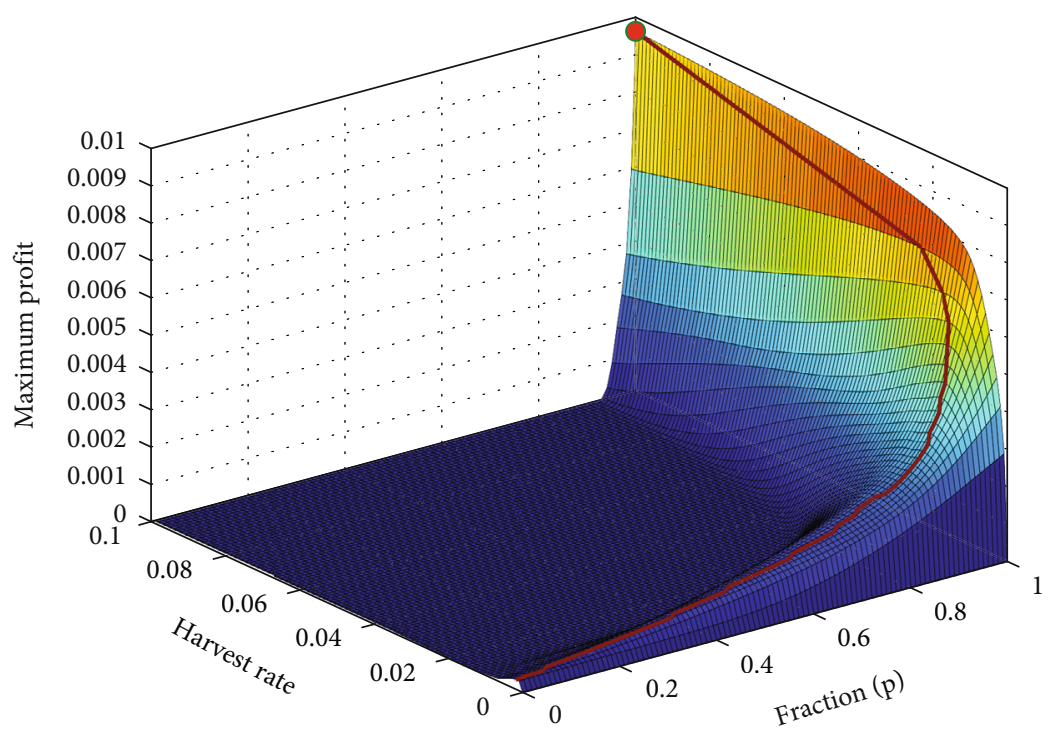

FIGURE 7: Simulation results, using system (18), including both African catfish and Nile tilapia with proportional harvesting rates, i.e., $\vec{h}_{p}=((1-p) h,(1-p) h, p h, p h,(1-p) h, p h)$ where $0 \leq p \leq 1$. The initial values are chosen positive, and other parameter values can be found in Tables 3-5.

different harvesting rates), compared to harvesting in a system having Nile tilapia only or African catfish only.

\section{Discussion}

The major aim of this study was to compare financial profit and biomass outtakes in a two-species system versus single-species systems. To facilitate this comparison, a nonlinear deterministic stage-structured fishery model for the dynamics of African catfish, Nile tilapia, and two food resources has been developed. African catfish is classified into four stages to capture the cannibalistic behavior, while Nile tilapia is categorized into two stages; in addition, the fish feed on two separate food resources in a preferred order. We established the region where the model system (18) is biologically feasible and mathematically well posed. The analytical results revealed that the fish-free two food resource equilibrium point is asymptotically stable if the recovery potentials $R_{C}<1$ and $R_{T}<1$. Numerical simulations indicated one positive equilibrium solution for each set of parameters regardless of positive initial values. 
TABLE 6: Simulation results using optimal harvest rates found in MATLAB, using patternSearch. The columns present the maximum sustainable biomass yield (grams per litre and day) and maximum sustainable financial profit (USD per litre and day). The rows indicate the fish stock scenarios.

\begin{tabular}{lcc}
\hline & $\begin{array}{c}\text { Maximum biomass } \\
\text { yield }\end{array}$ & $\begin{array}{c}\text { Maximum financial } \\
\text { profit }\end{array}$ \\
\hline Only Nile tilapia & 0.0024 & 0.0074 \\
Only African catfish & 0.0014 & 0.0057 \\
Both species & 0.0027 & 0.0081 \\
\hline
\end{tabular}

We established the two-species system to be better in both financial profit and biomass outtakes, compared to a single-species fish stock. Considering equal harvesting rates on both African catfish and Nile tilapia, results show that the impact of harvesting on population size structure is negative. The negative impact signifies a decrease in the fraction of juveniles in the system. This is because African Catfish is cannibalistic and predates on Nile tilapia.

Applying optimal harvest rates for harvesting both Nile tilapia and African catfish, African catfish only, and Nile tilapia only to maximize biomass yield and financial profits, our findings to some extent agree with $[63,64]$, in that, small fisheries using ponds or small lakes should implement both African catfish and Nile tilapia to harvest more biomass yield and gain more financial profits.

We emphasize that our findings are based on the model system (18); to prove these results, one should compare two species versus one species in fisheries, alternatively corroborating our findings, using different models. This study can be extended by analyzing a fishery model where there are more than two fish species and more food resources to make the model more realistic. Another direction for future research would be to investigate under what conditions the hydra effect occurs in cannibalistic predator prey models, cf. $[65,66]$.

\section{Data Availability}

The parameter input values used in the simulations were obtained from literature. They are summarized in Tables 3-5.

\section{Conflicts of Interest}

The authors declare that they have no conflict of interest.

\section{Acknowledgments}

We are very grateful to the financial supported extended by Sida Phase IV bilateral program with Makerere University (2015-2020 project 316) "Capacity building in Mathematics and its application."

\section{References}

[1] C. Béné, M. Barange, R. Subasinghe et al., "Feeding 9 billion by 2050-putting fish back on the menu," Food Security, vol. 7, no. 2, pp. 261-274, 2015.
[2] M. C. Beveridge, S. Thilsted, M. Phillips, M. Metian, M. Troell, and S. Hall, "Meeting the food and nutrition needs of the poor: the role of fish and the opportunities and challenges emerging from the rise of aquaculturea," Journal of Fish Biology, vol. 83, no. 4, pp. 1067-1084, 2013.

[3] F. Fao, The State of World Fisheries and Aquaculture. Opportunities and challenges, Food and Agriculture Organization of the United Nations, 2012.

[4] R. O. Abila, K. O. Odongkara, and P. O. Onyango, "Distribution of economic benefits from the fisheries of Lake Victoria," in Proceedings of the 11th World Lakes Conference-Proceedings, pp. 87-92, Nairobi, Kenya, 2006.

[5] J. P. Mpele, Y. Nkansah-Gyekye, and O. D. Makinde, "Estimating sustainable harvests of Lake Victoria fishery," International Journal of Applied Mathematics, vol. 27, no. 4, pp. 407-416, 2014.

[6] M. Njiru, M. van der Knaap, A. Taabu-Munyaho, C. Nyamweya, R. Kayanda, and B. Marshall, "Management of Lake Victoria fishery: are we looking for easy solutions?," Aquatic Ecosystem Health \& Management, vol. 17, no. 1, pp. 70-79, 2014.

[7] V. Volterra, "Variations and fluctuations of the numbers of individuals in coexisting animal populations," ICES Journal of Marine Science, vol. 131, 1927.

[8] A. Daci and A. Spaho, "Bifurcation in a dynamical system: harvest models," in International Conference on Research and Engineering-Challenges Toward the Future, pp. 24-25, Albania, 2013.

[9] T. Kar and K. Chaudhuri, "Harvesting in a twoprey onepredator fishery: a bioeconomic model," The ANZIAM Journal, vol. 45, no. 3, pp. 443-456, 2004.

[10] T. K. Kar and K. Chaudhuri, "On non-selective harvesting of two competing fish species in the presence of toxicity," Ecological Modelling, vol. 161, no. 1-2, pp. 125-137, 2003.

[11] D. L. Ragozin and G. Brown Jr., "Harvest policies and nonmarket valuation in a predator - prey system," Journal of Environmental Economics and Management, vol. 12, no. 2, pp. 155-168, 1985.

[12] E. Tromeur and N. Loeuille, "Balancing yield with resilience and conservation objectives in harvested predator-prey communities," Oikos, vol. 126, no. 12, pp. 1780-1789, 2017.

[13] J. Cushing, "A size-structured model for cannibalism," Theoretical Population Biology, vol. 42, no. 3, pp. 347-361, 1992.

[14] J. M. Cushing, "A competition model for size-structured species," SIAM Journal on Applied Mathematics, vol. 49, no. 3, pp. 838-858, 1989.

[15] A. M. de Roos, "A Gentle Introduction to Physiologically Structured Population Models," in Structured-Population Models in Marine, Terrestrial, and Freshwater Systems, pp. 119-204, Springer, 1997.

[16] J. Z. Farkas and T. Hagen, "Stability and regularity results for a size-structured population model," Journal of Mathematical Analysis and Applications, vol. 328, no. 1, pp. 119-136, 2007.

[17] J. Metz and O. Diekmann, "Formulating models for structured populations," in The Dynamics of Physiologically Structured Populations, pp. 78-135, Springer, 1986.

[18] L. Persson, K. Leonardsson, A. M. De Roos, M. Gyllenberg, and B. Christensen, "Ontogenetic scaling of foraging rates and the dynamics of a size-structured consumer-resource model," Theoretical Population Biology, vol. 54, no. 3, pp. 270-293, 1998. 
[19] F. Van den Bosch and W. Gabriel, "Cannibalism in an agestructured predator-prey system," Bulletin of Mathematical Biology, vol. 59, no. 3, pp. 551-567, 1997.

[20] Y. Cao, J. Fan, and T. C. Gard, "The effects of state-dependent time delay on a stage-structured population growth model," Nonlinear Analysis: Theory Methods \& Applications, vol. 19, no. 2, pp. 95-105, 1992.

[21] A. M. De Roos, T. Schellekens, T. Van Kooten, K. Van De Wolfshaar, D. Claessen, and L. Persson, "Simplifying a physiologically structured population model to a stage- structured biomass model," Theoretical Population Biology, vol. 73, no. 1, pp. 47-62, 2008.

[22] S. A. Gourley and Y. Kuang, "A stage structured predator-prey model and its dependence on maturation delay and death rate," Journal of Mathematical Biology, vol. 49, no. 2, pp. 188-200, 2004.

[23] N. L. Lundström, N. Loeuille, X. Meng, M. Bodin, and Å. Brännström, "Meeting yield and conservation objectives by harvesting both juveniles and adults," The American Naturalist, vol. 193, no. 3, pp. 373-390, 2019.

[24] X. Meng, N. L. Lundström, M. Bodin, and Å. Brännström, "Dynamics and management of stage-structured fish stocks," Bulletin of Mathematical Biology, vol. 75, no. 1, pp. 1-23, 2013.

[25] L. W. Botsford, "Optimal fishery policy for sizespecific, density-dependent population models," Journal of Mathematical Biology, vol. 12, no. 3, pp. 265-293, 1981.

[26] D. Claessen, A. M. de Roos, and L. Persson, "Dwarfs and giants: cannibalism and competition in size-structured populations," The American Naturalist, vol. 155, no. 2, pp. 219237, 2000.

[27] D. Claessen, A. M. De Roos, and L. Persson, "Population dynamic theory of size-dependent cannibalism," Proceedings of the Royal Society of London. Series B: Biological Sciences, vol. 271, no. 1537, pp. 333-340, 2004.

[28] H. Landahl and B. Hansen, "A three stage population model with cannibalism," Bulletin of Mathematical Biology, vol. 37, no. 1, pp. 11-17, 1975.

[29] L. Persson, P. Byström, and E. Wahlström, "Cannibalism and competition in Eurasian perch: population dynamics of an ontogenetic omnivore," Ecology, vol. 81, no. 4, pp. 10581071, 2000.

[30] L. Persson, D. Claessen, A. M. De Roos et al., "Cannibalism in a size-structured population: energy extraction and control," Ecological Monographs, vol. 74, no. 1, pp. 135-157, 2004.

[31] M. Bruton, "The food and feeding behaviour ofClarias gariepinus(Pisces: Clariidae) in Lake Sibaya, South Africa, with emphasis on its role as a predator of cichlids," The Transactions of the Zoological Society of London, vol. 35, no. 1, pp. 47-114, 1979.

[32] P. Spataru, W. Viveen, and M. Gophen, "Food composition of Clarias gariepinus (= C. lazera)(Cypriniformes, Clariidae) in Lake Kinneret (Israel)," Hydrobiologia, vol. 144, no. 1, pp. 77-82, 1987.

[33] W. Viveen, C. Richter, P. Van Oordt, J. Janssen, and E. Huisman, Practical Manual for the Culture of the African Catfish (Clarias gariepinus), Wageningen University \& Research, Wageningen, Netherlands, 1986.

[34] W. W. Mwanja, G. C. Booton, L. Kaufman, and P. A. Fuerst, "A profile of the introduced Oreochromis niloticus (pisces:
Teleostei) populations in Lake Victoria region in relation to its putative origin of Lakes Edward and Albert (Uganda-E. Africa) based on random amplified polymorphic DNA analysis," African Journal of Biotechnology, vol. 7, no. 11, pp. 17691773, 2008.

[35] E. Y. Mohammed and Z. B. Uraguchi, Impacts of Climate Change on Fisheries: Implications for Food Security in SubSaharan Africa, Global Food Security, Nova Science Publishers, Inc,, 2013.

[36] M. Mwanja, C. Ondhoro, M. Sserwada, P. Achieng, R. Ddungu, and W. Mwanja, "Morphological variation of Nile tilapia populations from major water bodies of Uganda," Uganda Journal of Agricultural Sciences, vol. 17, no. 1, pp. 21-32, 2017.

[37] P. Fuerst, W. Mwanja, and L. Kaufman, “The genetic history of the introduced Nile tilapia of Lake Victoria (Uganda-E. Africa): the population structure of Oreochromis niloticus (pisces: Cichlidae) revealed by DNAmicrosatellitemarkers.," in Tilapia Aquaculture in the 21st Century Proceedings from the Fifth International Symposium on Tilapia in Aquaculture, pp. 30-40, Rio de Janeiro, Brazil, 2000.

[38] O. N. Otieno, N. Kitaka, and J. Njiru, "Lengthweight relationship, condition factor, length at first maturity and sex ratio of Nile tilapia, Oreochromis niloticus in Lake Naivasha, Kenya," International Journal of Fisheries and Aquatic Studies, vol. 2, no. 2, pp. 67-72, 2014.

[39] E. Dadebo, "Filter feeding habit of the African catfish Clarias gariepinus Burchell, 1822 (pisces: Clariidae) in Lake Chamo, Ethiopia," Ethiopian Journal of Biological Sciences, vol. 8, no. 1, pp. 15-30, 2009.

[40] L. A. Demeke Admassu and Z. Tadesse, "The food and feeding habits of the African catfish, Clarias gariepinus (Burchell). Lake Babogaya, Ethiopia," Global Journal of Fisheries and Aquaculture, vol. 3, no. 4, pp. 211-220, 2015.

[41] A. Tesfahun, "Feeding biology of the African catfish Clarias gariepinus (Burchell) in some of Ethiopian lakes: a review," International Journal of Fauna and Biological Studies, vol. 5, no. 1, pp. 19-23, 2018.

[42] B. Ghosh, T. Kar, and T. Legovic, "Relationship between exploitation, oscillation, MSY and extinction," Mathematical Biosciences, vol. 256, pp. 1-9, 2014.

[43] B. Barman and B. Ghosh, "Dynamics of a spatially coupled model with delayed prey dispersal," International Journal of Modelling and Simulation, vol. 41, pp. 1-15, 2021.

[44] P. Lancaster and M. Tismenetsky, The Theory of Matrices, Academic Press, New York, NY, USA, 1969.

[45] J. D. Murray, Mathematical Biology, vol. 19 of Biomathematics, Berlin, Germany, Springer, 1989.

[46] A. Kurbanov and B. Kamilov, "Maturation of African catfish, Clarias gariepinus, in condition of seasonal climate of Uzbekistan," International Journal of Fisheries and Aquatic Studies, vol. 5, no. 2, pp. 236-239, 2017.

[47] E. Yongo, N. Outa, K. Kito, and Y. Matsushita, "Studies on the biology of Nile tilapia (Oreochromis niloticus) in Lake Victoria, Kenya: in light of intense fishing pressure," African Journal of Aquatic Science, vol. 43, no. 2, pp. 195-198, 2018.

[48] J. H. Brown, J. F. Gillooly, A. P. Allen, V. M. Savage, and G. B. West, "Toward a metabolic theory of ecology," Ecology, vol. 85, no. 7, pp. 1771-1789, 2004.

[49] R. H. Peters and R. H. Peters, The Ecological Implications of Body Size, volume 2, Cambridge University Press, 1986. 
[50] P. Yodzis and S. Innes, "Body size and consumer-resource dynamics," The American Naturalist, vol. 139, no. 6, pp. 1151-1175, 1992.

[51] P. J. Hansen, P. K. Bjørnsen, and B. W. Hansen, “Zooplankton grazing and growth: scaling within the $2-2,-\mu \mathrm{m}$ body size range," Limnology and Oceanography, vol. 42, no. 4, pp. 687704, 1997.

[52] J. F. Gillooly, J. H. Brown, G. B. West, V. M. Savage, and E. L. Charnov, "Effects of size and temperature on metabolic rate," Science, vol. 293, no. 5538, pp. 2248-2251, 2001.

[53] O. Lessmark, "Competition between Perch (Perca fluviatilis) and Roach (Rutilus rutilus)," in South Swedish Lakes, Lund University, 1983.

[54] P. Byström and E. García-Berthou, "Density dependent growth and size specific competitive interactions in young fish," Oikos, vol. 86, no. 2, pp. 217-232, 1999.

[55] V. Okomoda, W. Aminem, A. Hassan, and C. Martins, "Effects of feeding frequency on fry and fingerlings of African catfish _Clarias gariepinus_," Aquaculture, vol. 511, p. 734232, 2019.

[56] R. K. Upadhyay, S. Tiwari, and P. Roy, "Complex dynamics of wetland ecosystem with nonlinear harvesting: application to Chilika Lake in Odisha, India," International Journal of Bifurcation and Chaos, vol. 25, no. 7, p. 1540016, 2015.

[57] A. Edvardsen, M. Zhou, K. S. Tande, and Y. Zhu, "Zooplankton population dynamics: measuring in situ growth and mortality rates using an optical plankton counter," Marine Ecology Progress Series, vol. 227, pp. 205-219, 2002.

[58] R. Pinto-Coelho, B. Pinel-Alloul, G. Méthot, and K. E. Havens, "Crustacean zooplankton in lakes and reservoirs of temperate and tropical regions: variation with trophic status," Canadian Journal of Fisheries and Aquatic Sciences, vol. 62, no. 2, pp. 348-361, 2005.

[59] S. Raw, B. Tiwari, and P. Mishra, "Analysis of a plankton-fish model with external toxicity and nonlinear harvesting," Ricerche di Matematica, vol. 69, pp. 1-29, 2020.

[60] M. Kunda, A. Harun-Al-Rashid, F. Morshed, A. Islam, and S. K. Mazumder, "Production of tilapia (Oreochromis niloticus) fingerling in hapa using swim-up fry involving women in the haor region of Bangladesh," IOSR Journal of Agriculture and Veterinary Science, vol. 7, no. 10, pp. 29-35, 2014.

[61] J. Gwahaba, "Effects of fishing on the Tilapia nilotica (Linne 1757) population in Lake George, Uganda over the past 20 years," African Journal of Ecology, vol. 11, no. 3-4, pp. 317328,1973 .

[62] J. L. Keyombe, E. Waithaka, and B. Obegi, "Length-weight relationship and condition factor of Clarias gariepinus in Lake Naivasha, Kenya," International Journal of Fisheries and Aquatic Studies, vol. 2, no. 6, pp. 382-385, 2015.

[63] M. Ibrahem, I. Shaheed, H. Yazeed, and H. Korani, "Assessment of the susceptibility of polyculture reared African catfish and Nile tilapia to Edwardsiella tarda," Journal of American Science, vol. 7, no. 3, pp. 779-786, 2011.

[64] N. Ibrahim and G. E. Naggar, "Water quality, fish production and economics of Nile tilapia, Oreochromis niloticus, and African catfish, Clarias gariepinus, monoculture and polycultures," Journal of the World Aquaculture Society, vol. 41, no. 4 , pp. 574-582, 2010.
[65] P. D. Adhikary, S. Mukherjee, and B. Ghosh, "Bifurcations and hydra effects in Bazykin's predator-prey model," Theoretical Population Biology, vol. 140, pp. 44-53, 2021.

[66] B. Ghosh, O. L. Zhdanova, B. Barman, and E. Y. Frisman, "Dynamics of stage-structure predator-prey systems under density-dependent effect and mortality," Ecological Complexity, vol. 41, article 100812, 2020. 